\title{
Determination of pesticides residues in quinoa (Chenopodium quinoa Willd) using QuEChERS and LC-MS/MS
}

\author{
Franz Zirena Vilca ${ }^{1,2 *}$, Graziela Cristina Rossi. Moura Andrade ${ }^{2}$, Walter Alejandro. Zamalloa Cuba ${ }^{3}$, \\ Valdemar Luiz. Tornisielo² \\ ${ }^{1}$ Escuela de Posgrado de la Universidad Nacional del Altiplano, Av Floral 1153 Puno-Perú, ${ }^{2}$ Centro de Energia Nuclear na Agricultura, \\ Laboratório de Ecotoxicologia, Avenida Centenário 303, 13416-903 Piracicaba, SP, Brazil, ${ }^{3}$ Escuela Profesional de Ingeniería Química de la \\ Universidad Nacional del Altiplano, Av Floral S/N Puno-Peru
}

\section{A B S T R A C T}

The QuEChERS method was optimized and validated for the determination of 40 pesticides in 37 samples of quinoa from the harvest 2010 2011 in Puno - Peru. The method involves extraction with $1 \%$ acetic acid acetonitrile with $\mathrm{CH}_{3} \mathrm{COONa}$ anhydrous and $\mathrm{MgSO}$ followed by dispersive solid-phase extraction with PSA and C18. Analyses were performed with LC-MS/MS using C18 column $150 \mathrm{~mm} \times 2.1 \times 3.5 \mu \mathrm{m}$, water and acetonitrile $0.1 \%$ formic acid used as mobile phase. Spiked quinoa blank at 0.01 and $0.1 \mathrm{mg} \mathrm{kg}^{-1}$ was employed to evaluate recovery ranging from the 31.6 and $125.1 \%$ with RSD $\leq 23$. The method showed linearity $r 2 \geq 0.99$ and limits of quantification ranged from 0.001 and $0.01 \mathrm{mg} \mathrm{kg}^{-1}$, and was not observed a matrix effects. No pesticides residues were observed in the analyzed samples.

Keywords: Andean grains; Multiple residues; Incan culture; Pesticides; Liquid chromatography

\section{INTRODUCTION}

Quinoa is an important grain crop, which has been cultivated for over 5000 years in the Andean region, and was important to the Incas for its high nutritional value (Stentiford et al., 2003; Nakata et al., 2006; Jacobsen and Christiansen, 2016). The leading producers of quinoa are Peru and Bolivia, however there is increasing interest in its production due to its tolerance to poor soils and water shortages, although its productivity $\left(8595 \mathrm{Hg} \mathrm{ha}^{-1}\right)$ is low in comparison with corn and rice (FAO, 2015). In 2014, 192,506.00 tons of quinoa were produced in the world and, exclusively in South America, with 114,343.00 tons in Peru, and 7,354.00 tons in Bolivia (da Silva et al., 2013). The quinoa grain is regarded as a food with high nutritional value, due to its high protein and essential amino acids contents and it being a gluten-free substitute for conventional cereals (Guzzella et al., 2005; Djaman et al.,2016).

Hundreds of pesticides are used in agricultural practices in the world, and it is not unusual to find residues of these compounds in food products, especially fruits and vegetables. After the establishment of the maximum residue limits (MRL) to protect the environment and the health of consumers, the determination of residues of pesticides in food matrices has become a requirement due to toxicity and stability of these compounds (Vuorinen et al., 2006; Tiyagi et al., 2015; Mitkova 2016). In order to protect animal and human health, the European Union developed Regulation (EC) No 396/2005 that regulates the limits that apply to different food products and establishes a maximum limit applicable by default.

The US MRLs for quinoa are $3 \mathrm{mg} \mathrm{kg}^{-1}$ azoxystrobin, $0.5 \mathrm{mg} \mathrm{kg}^{-1}$ dichlorvos, $5 \mathrm{mg} \mathrm{kg}^{-1}$ ethofenprox, $5 \mathrm{mg} \mathrm{kg}^{-1}$ glyphosate, $3 \mathrm{mg} \mathrm{kg}^{-1}$ propiconazole, $0.04 \mathrm{mg} \mathrm{kg}^{-1}$ spinetoram, $0.02 \mathrm{mg} \mathrm{kg}^{-1}$ spinosad, and $2 \mathrm{mg} \mathrm{kg}^{-1}$ sulfuryl fluoride. The European Commission MRLs are in the text below and in Brazil there are no limits for this crop (Diez et al., 2006; Radman et al., 2015).

The QuEChERS (Quick, Easy, Cheap, Effective, Rugged and Safe) extraction method introduced by

*Corresponding author:

Franz Zirena Vilca, Escuela de Posgrado de la Universidad Nacional del Altiplano, Av Floral 1153 Puno-Perú. E-mail: franzvilca@usp.br

Received: 04 October 2017; $\quad$ Accepted: 12 March 2018 
Anastassiades(Anastassiades et al., 2003b) has been applied and modified for several studies in the world for residue analysis in different matrices mostly used in chromatographic systems coupled with mass spectrometry LC/MS/MS and GC/MS (Pinto et al., 2011; Feeley and Brouwer, 2000; Kasiotis et al., 2015; Cesar et al., 2014). In the scientific literature there are few studies related to the evaluation of contaminants in quinoa (Worm et al., 2006, Demirtas at al. 2015; Barriga et al., 2016); the objective of this work was to adjust and validate the QuEChERS method and analysis by LC-MS/MS for the determination of pesticides in 37 quinoa samples from Puno-Peru.

\section{MATERIALS AND METHODS}

\section{Reagents and materials}

Analytical standards of the compounds containing more than $98.9 \%$ of the purity were obtained from Dr. Ehrenstorfer (Augsburg, Germany) and ChemService (West Chester, PA, USA). Individual stock solutions were prepared at a concentration of $1 \mathrm{mg} \mathrm{mL}^{-1}$ with acetonitrile HPLC/Spectro that was purchased from Tedia Company Inc. (Fairfield, OH, USA) and stored at $-18{ }^{\circ} \mathrm{C}$. Working solutions of appropriate dilution for use were prepared in an 80: $20(\mathrm{v} / \mathrm{v})$ water and acetonitrile $0.1 \%$ acetic acid from J.T. Baker (Phillipsburg, NJ, USA). Formic acid 88\%, sodium acetate $\left(\mathrm{CH}_{3} \mathrm{COONa}\right)$ and magnesium sulfate $\left(\mathrm{MgSO}_{4}\right)$ anhydrous were purchased from J.T. Baker and PSA from Varian Inc. (Palo Alto, CA, USA).

\section{LC-MS/MS analyses}

The analyses were carried out in the LC-MS/MS system: Liquid Agilent (Wilmington, USA) Chromatograph 1200 equipped with a binary pump and automatic sampler G1367C. The chromatographic separations were carried out using an Agilent Zorbax C18 column $(150 \mathrm{~mm}$ x $2.1 \mathrm{~mm}, 3.5-\mathrm{mm}$ particle size). The mobile phases were Milli-QÒwater (Millipore; Bedford, USA) (A) and acetonitrile (B), with $0.1 \%$ formic acid in both. The gradient program started at 20\% B hold on for $10 \mathrm{~min}$, with linear gradient until $90 \%$ B for $15 \mathrm{~min}$. After running for $25 \mathrm{~min}$, the re-equilibrium time (post time) was 10 min using $20 \% \mathrm{~B}$. The flow remained constant at $0.25 \mathrm{~mL} \mathrm{~min}^{-1}$, the column temperature was maintained at $25^{\circ} \mathrm{C}$, and the injection volume was $2 \mathrm{~mL}$ (Fig.1).

A spectrometer of mass Quadruple Triple 6430 as a detector was used. The ESI parameters in the positive ionization mode were gas flow of $11.0 \mathrm{~L} \mathrm{~min}^{-1}$, nebulizer pressure was 43 psi, gas temperature was $350^{\circ} \mathrm{C}$, and capillary voltage was $3500 \mathrm{~V}$. Nitrogen $99.99 \%$ was used as nebulizer and $99.9999 \%$ as collision gas. For data acquisition, the software Agilent Mass Hunter was used. For the detection in the MS/MS, the MRM (multiple reaction monitoring) mode was used (Andrade et al., 2015).

\section{Sample preparation}

The QuEChERS method was originally developed for vegetables samples with over $75 \%$ moisture (Anastassiades et al., 2003a). However, some studies have adopted the

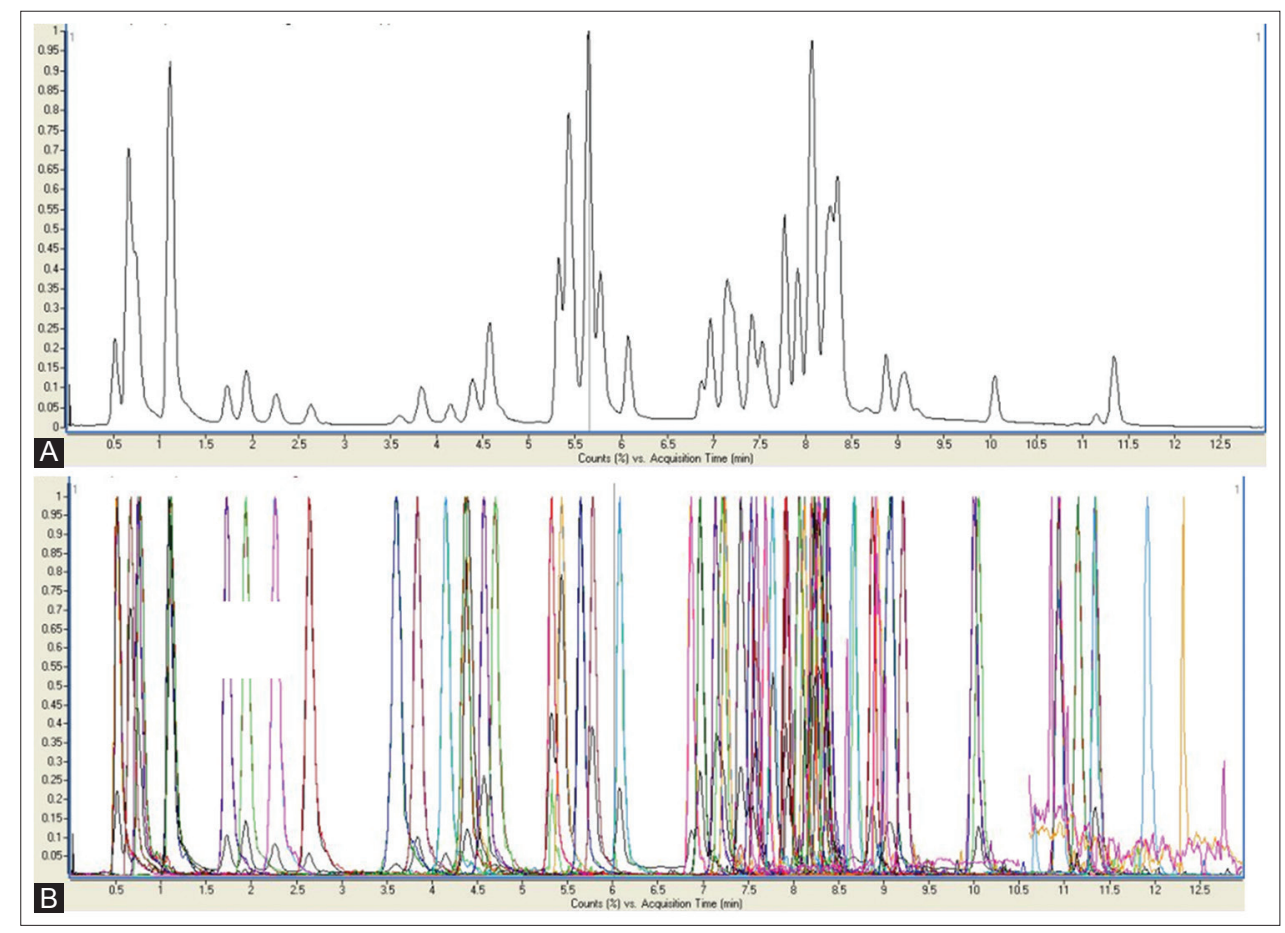

Fig1. A) Total lon Chromatogram B) Transitions for the 40 compounds analyzed in Dynamic MRM mode. 
method to be used for samples with low moisture content $<25 \%$, such as cereals, reducing the amount of sample and added water to facilitate the interaction of the solvent with the pores of the sample (Radovic et al., 2015, Jakimska et al., 2014, Wen et al., 2014).

In this study $100 \mathrm{~g}$ of quinoa samples were weighed and $300 \mathrm{~mL}$ of ultra-pure of water added and mixed to obtain a homogeneous paste. After, $15 \mathrm{~g}$ of homogeneous paste were weighed into a $50 \mathrm{~mL}$ polypropylene centrifuge tube which was added to $15 \mathrm{~mL}$ of acetonitrile $1 \%$ acetic acid, $6 \mathrm{~g}$ of $\mathrm{MgSO}_{4}$ and $1.5 \mathrm{~g}$ of anhydrous $\mathrm{CH}_{3} \mathrm{COONa}$. The samples were shaken by hand for $1 \mathrm{~min}$, and then centrifuged at $5000 \mathrm{rpm}$ for $5 \mathrm{~min}$. To the clean-up an aliquot of $1 \mathrm{ml}$ of supernatant was transferred to a $2 \mathrm{~mL}$ centrifuge tube containing $50 \mathrm{mg}$ of PSA, $50 \mathrm{mg}$ of C18 and $150 \mathrm{mg}$ of $\mathrm{MgSO}_{4}$, shaken manually for 30 seconds and centrifuged at $5000 \mathrm{rpm}$ for $5 \mathrm{~min} ; 500 \mu \mathrm{L}$ of this extract was filtered with $0.20-\mu \mathrm{m}$ mesh Teflon filters (Whatman, Florham Park, USA) and placed in a $1.5 \mathrm{~mL}$ amber vial, and then injecting in the LC-MS/MS system for analysis.

Matrix-matched standards were prepared using blank samples after the samples spiked and was left to stand for one hour, and then were extracted according to the sample preparation procedure mentioned above. We obtained certified organic quinoa where chemicals had not been applied (blank values were not higher than $30 \%$ of the LQ).

\section{Samples}

A total of 37 quinoa samples from eight agricultural districts of Puno, Peru were analyzed. All samples belonged to harvest 2010 - 2011; three varieties and eight ecotypes of this Andean grain were collected in the sampling process. A non-probability sampling process was used, taking into consideration the importance of the production area; to which was collected from a five sub sample of the one kilogram and then homogenized to collect a representative one kilogram, the sample was processed in a food processor, and selected $200 \mathrm{~g}$ of the sub sample of which was designed for analysis.

\section{Validation of analytical method}

The validation of the analytical method was carried out with the following parameters: linearity, limits of quantification, precision, accuracy and repeatability (Bluthgen, 2001, Cogne et al., 1995). The linearity was determined by construction of standard curves in seven concentrations: 0.0025; 0.005; 0.010; 0.020; 0.040; 0.100 and $0.200 \mathrm{mg} \mathrm{L}^{-1}$. The curve was prepared in solvent and matrix of quinoa extract (matrix-matched standards).

The evaluation of the effect matrix was made using of the ratio of the slopes, in solvent and in matrix. Depending on the decrease or increase in the percentage of the slope, different matrix effects could be observed: it was considered to be a mild signal suppression or enhancement effect between $-20 \%$ and $0 \%$ and between $0 \%$ and $+20 \%$; it was considered to be of medium effect when the slope values were between $-50 \%$ and $-20 \%$ or $+20 \%$ and $+50 \%$; and it was considered to be a strong effect of signal suppression or enhancement below $-50 \%$ or above $+50 \%$ (Ramalhosa et al., 2009).

The Limit of Quantification (LQ) were estimated based on the injection of matrix-matched solutions at concentrations of $0.0025 \mathrm{mg} \mathrm{L}^{-1}$, and expressed as three and ten times, respectively, the signal-to-noise $(\mathrm{S} / \mathrm{N})$ ratio in the transition MRM of the quantifying ion.

For the recovery study, spiked quinoa samples were prepared at 1 LQ and 10 LQ spiking levels. The QuEChERS method was carried out seven times at each spiking level. Precision was expressed as the relative standard deviation for repeatability (RSDr), and relative standard deviation for reproducibility (RSDR) from the recovery determinations at the two spiking concentrations.

\section{RESULTS AND DISCUSSION}

The main objective of this study was to identify an inexpensive and efficient method for the determination of pesticide residues in quinoa. The modified QuEchERS method in the LC-MS/MS system and MRM mode, using PSA and C18 in clean up, presented as an efficient method for that purpose.

\section{Compounds identification}

Retention time and two transitions in MRM mode were used for the identification of pesticide residues. The monitored ions for each compound are listed in Table 1. (Andrade et al., 2015).

\section{Validation method and quality control}

The concentration range ( 0.0025 to $\left.0.200 \mu \mathrm{g} \mathrm{mL} \mathrm{m}^{-1}\right)$ presented linearity with the analytical signal, indicated by the values of determination coefficient ( $\mathrm{r} 2$ ) being greater than 0.99 for all compounds in solvent and matrix. There was no significant matrix effect for compounds and therefore the sample could be quantified on the curve of the solvent. Table 2 shows the effect matrix values and the limits of quantification of the pesticides. LQ's was reached on the order of $0.001 \mathrm{mg} \mathrm{kg}^{-1}$, and that there are no MRLs established for this crop.

In the recoveries at a concentration of $0.01 \mathrm{mg} \mathrm{kg}^{-1}$ we observed that $61 \%$ of the 42 validated compounds exhibit recoveries above $70 \%$, this being lowest for thiabendazole 
Table 1: Compounds retention time $\left(\mathrm{t}_{\mathrm{r}}\right)$, precursor ion and product ion of quantification (qt) and qualification (ql), fragmentation energy (Frag), and collision energy (CE) of transitions 1 and 2

\begin{tabular}{|c|c|c|c|c|c|c|c|}
\hline Compounds & $\operatorname{tr}$ & Precursor ion & Product ion (qt) & CE (1) & Product ion (ql) & CE (2) & Frag \\
\hline Acetamiprid & 7.4 & 223.1 & 126.0 & 20 & 99.0 & 39 & 90 \\
\hline Aaldicarb & 8.6 & 213.0 & 116.0 & 5 & 89.1 & 10 & 110 \\
\hline Atrazine & 10.3 & 216.1 & 174.0 & 16 & 104.0 & 32 & 120 \\
\hline Azoxystrobin & 11.9 & 404.1 & 372.0 & 8 & 344.1 & 24 & 100 \\
\hline Bbenalaxyl & 13.4 & 326.2 & 294.1 & 4 & 148.1 & 16 & 100 \\
\hline Bromacil & 8.8 & 261.0 & 204.9 & 9 & 188.0 & 26 & 70 \\
\hline Bromuconazole & 11.8 & 376.0 & 158.9 & 24 & 89.0 & 104 & 130 \\
\hline Buprofezin & 13.4 & 306.2 & 201.0 & 8 & 116.0 & 12 & 90 \\
\hline Carbaryl & 10.2 & 202.1 & 145.0 & 0 & 127.0 & 28 & 55 \\
\hline Carbofuran & 9.9 & 222.1 & 165.0 & 8 & 123.0 & 20 & 70 \\
\hline Cymoxanil & 8 & 199.1 & 128.0 & 0 & 83.0 & 12 & 50 \\
\hline Cyproconazole & 11.5 & 292.1 & 125.0 & 32 & 70.1 & 16 & 110 \\
\hline Diflubenzuron & 12.5 & 311.0 & 158.0 & 10 & 141.0 & 35 & 120 \\
\hline Dimethoate & 7.2 & 230.0 & 198.9 & 4 & 124.9 & 20 & 60 \\
\hline Diuron & 10.5 & 233.0 & 159.9 & 24 & 72.0 & 20 & 100 \\
\hline Fenamiphos & 11.8 & 304.1 & 216.9 & 20 & 201.9 & 36 & 110 \\
\hline Fenarimol & 11.8 & 331.0 & 189.0 & 52 & 111.0 & 64 & 140 \\
\hline Fenoxycarb & 12.6 & 302.1 & 256.1 & 8 & 116.0 & 4 & 90 \\
\hline Fipronil & 13.1 & 437.0 & 368.2 & 13 & 314.9 & 25 & 130 \\
\hline Flazasulfuron & 11 & 408.1 & 182.0 & 12 & 139.0 & 40 & 110 \\
\hline Imidacloprid & 6.7 & 256.1 & 209.0 & 12 & 175.1 & 16 & 90 \\
\hline Iprodione & 12.6 & 330.0 & 245.0 & 10 & ---- & --- & 90 \\
\hline Linuron & 11.8 & 249.0 & 159.9 & 12 & 132.9 & 36 & 100 \\
\hline Malathion & 12.6 & 331.1 & 284.9 & 0 & 127.0 & 8 & 70 \\
\hline Methamidophos & 11.6 & 142.0 & 125.0 & 8 & 94.0 & 10 & 70 \\
\hline Methiocarb & 1.9 & 226.1 & 169.0 & 4 & 121.0 & 16 & 60 \\
\hline Metribuzin & 9.5 & 215.1 & 187.2 & 13 & 74.0 & 36 & 85 \\
\hline Monocrotophos & 2.9 & 224.1 & 193.0 & 0 & 127.0 & 12 & 60 \\
\hline Monuron & 9 & 199.1 & 126.0 & 24 & 99.0 & 40 & 85 \\
\hline Oxamyl & 3 & 237.0 & 90.1 & 0 & 72.1 & 15 & 60 \\
\hline Pyrimethanil & 9.5 & 200.1 & 181.1 & 47 & 107.0 & 21 & 150 \\
\hline Pirimicarb & 4.1 & 239.1 & 182.1 & 12 & 72.0 & 20 & 90 \\
\hline Pirimiphos-methyl & 13.4 & 306.1 & 201.1 & 8 & 106.0 & 24 & 90 \\
\hline Prochloraz & 11.2 & 376.0 & 307.9 & 4 & 70.0 & 24 & 85 \\
\hline Prometryn & 9.7 & 242.1 & 200.0 & 16 & 158.0 & 20 & 120 \\
\hline Tebuconazole & 12.2 & 308.2 & 125.0 & 40 & 70.0 & 16 & 120 \\
\hline Thiabendazole & 2.3 & 202.0 & 175.0 & 24 & 131.0 & 36 & 140 \\
\hline Thiacloprid & 8.5 & 253.0 & 126.0 & 16 & 90.0 & 28 & 95 \\
\hline Triadimenol & 11.2 & 296.1 & 227.0 & 1 & 70.1 & 5 & 60 \\
\hline Triazophos & 12.7 & 314.1 & 162.0 & 16 & 119.0 & 36 & 100 \\
\hline
\end{tabular}

$(31.6 \%)$ and fenoxycarb (42.4\%); in the second level of fortification $0.01 \mathrm{mg} \mathrm{kg}^{-1}$ we observed that $90 \%$ of the compounds showed $\geq 70 \%$ and we observed $29.6 \%$ of the recovery for thiabendazole, these effects can be attributed to a slight interference matrix for these compounds. Table 2 shows the recovery values found in this study. According to Sanco, recoveries outside the range of $70-120 \%$ may be accepted, and where recovery is low but consistent (demonstrating good precision) a mean recovery below $70 \%$ may be acceptable (Bluthgen, 2001). The compound thiabendazole was not quantified in the samples due to low recovery in both concentrations studied.
The results of the study based on repeatability ranged from 2.1 to $20.3 \%$ (Table 2), with monuron presenting the greatest dispersion of results. However, these values showed good results, once the RSDs are within the recommended range for the multi-residue analysis of up to $20 \%$ (Bluthgen, 2001). Regarding the reproducibility, of the 40 pesticides validated, only two showed values greater than 20\% (dichlorvos and fipronil), however, within the acceptable range of recovery and RSD (Table 2).

All extracts of fortified samples injected together with the real samples to control quality in the analyses, showed 
Table 2: Matrix effect (ME\%), limit of quantification (LQ), MRL, recovery (\%), repeatability (RSDr) and relative standard deviation for reproducibility (RSDR)

\begin{tabular}{|c|c|c|c|c|c|c|c|c|c|}
\hline \multirow[t]{2}{*}{ Compounds } & \multirow[t]{2}{*}{ ME(\%) } & \multirow[t]{2}{*}{ LQ mg kg $^{-1}$} & \multirow[t]{2}{*}{ MRL E.U. } & \multicolumn{6}{|c|}{ Recovery \% $(n=7)$} \\
\hline & & & & 0.01 mg kg-1 & RSDr \% & $0.1 \mathrm{mg} \mathrm{kg-1}$ & RSDr \% & 0.01 mg kg-1 & RSDR \% \\
\hline Acetamiprid & -5.6 & 0.002 & 0.01 & 80.5 & 9.5 & 79.3 & 3.3 & 84.4 & 7.2 \\
\hline A aldicarb & -4.1 & 0.002 & 0.02 & 112.5 & 15.0 & 125.1 & 3.0 & 97.1 & 17.3 \\
\hline Atrazine & -1.4 & 0.003 & 0.1 & 93.7 & 6.6 & 95.7 & 4.4 & 97.7 & 5.9 \\
\hline Azoxystrobin & -16.1 & 0.002 & 0.05 & 65.6 & 9.3 & 72.2 & 3.8 & 71.3 & 6.0 \\
\hline Benalaxyl & -3.7 & 0.003 & 0.05 & 54.4 & 11.5 & 77.6 & 3.0 & 59.4 & 8.5 \\
\hline Bbromacil & -1.8 & 0.004 & - & 76.8 & 12.5 & 71.4 & 2.4 & 75.6 & 8.1 \\
\hline Bromuconazole & 1.5 & 0.01 & 0.2 & 73.2 & 9.7 & 81.9 & 4.3 & 78.7 & 9.1 \\
\hline Buprofezin & -1.2 & 0.003 & 0.05 & 81.9 & 8.8 & 89.6 & 2.8 & 84.1 & 7.0 \\
\hline Carbaryl & -3.6 & 0.002 & 0.5 & 77.0 & 9.6 & 75.0 & 4.1 & 79.0 & 7.5 \\
\hline Carbofuran & -3.5 & 0.002 & 0.01 & 72.6 & 9.3 & 74.3 & 3.3 & 76.9 & 7.8 \\
\hline Cymoxanil & -8.2 & 0.003 & 0.05 & 73.4 & 14.9 & 73.6 & 3.3 & 72.6 & 11.4 \\
\hline Cyproconazole & -0.2 & 0.003 & 0.1 & 74.2 & 7.9 & 80.2 & 3.5 & 75.4 & 7.6 \\
\hline Diflubenzuron & 6.7 & 0.01 & 0.05 & 55.9 & 12.1 & 89.7 & 6.6 & 52.7 & 17.6 \\
\hline Dimethoate & -9.8 & 0.004 & 0.02 & 87.0 & 5.3 & 78.4 & 4.0 & 91.8 & 8.9 \\
\hline Diuron & -2.9 & 0.003 & 0.01 & 63.7 & 8.7 & 72.3 & 2.1 & 64.9 & 6.5 \\
\hline Fenamiphos & -6.6 & 0.003 & 0.02 & 74.4 & 9.2 & 78.6 & 5.0 & 79.4 & 6.1 \\
\hline Fenarimol & 3 & 0.004 & 0.02 & 61.1 & 16.4 & 76.6 & 4.2 & 72.7 & 18.6 \\
\hline Fenoxycarb & 8.9 & 0.003 & 0.05 & 42.4 & 19.4 & 86.1 & 4.0 & 44.4 & 12.6 \\
\hline Fipronil & -1.8 & 0.002 & 0.005 & 69.0 & 15.8 & 92.4 & 10.5 & 75.6 & 30.4 \\
\hline Flazasulfuron & -11 & 0.001 & 0.01 & 47.3 & 11.7 & 64.8 & 3.7 & 45.1 & 7.1 \\
\hline Imidacloprid & -4.8 & 0.008 & 0.1 & 89.1 & 8.4 & 78.8 & 3.1 & 91.6 & 5.3 \\
\hline liprodione & 0.8 & 0.003 & 0.02 & 67.7 & 14.9 & 96.0 & 3.3 & 66.7 & 15.8 \\
\hline Linuron & 5.4 & 0.004 & 0.05 & 66.1 & 15.6 & 70.8 & 2.3 & 68.3 & 16.2 \\
\hline m Malathion & 9.8 & 0.004 & 8 & 53.0 & 11.1 & 64.4 & 3.0 & 57.0 & 10.1 \\
\hline Methamidophos & -4.6 & 0.002 & 0.01 & 69.2 & 8.3 & 69.8 & 4.6 & 74.6 & 15.4 \\
\hline Methiocarb & -6.7 & 0.001 & 0.1 & 65.0 & 10.3 & 69.5 & 4.7 & 69.3 & 11.9 \\
\hline Metribuzin & -3.9 & 0.002 & 0.1 & 83.5 & 3.7 & 94.5 & 2.7 & 85.8 & 9.0 \\
\hline Monocrotophos & -1.2 & 0.001 & 0.02 & 79.3 & 11.9 & 87.7 & 4.5 & 89.4 & 10.6 \\
\hline Monuron & -2.6 & 0.002 & 0.01 & 78.0 & 20.3 & 74.8 & 8.4 & 82.2 & 12.8 \\
\hline Oxamyl & -4.2 & 0.002 & 0.01 & 92.4 & 13.0 & 91.8 & 11.2 & 112.9 & 18.5 \\
\hline Pyrimethanil & 5.4 & 0.002 & 0.01 & 83.9 & 12.1 & 84.5 & 3.5 & 87.2 & 5.7 \\
\hline Pirimicarb & -3.8 & 0.003 & 0.2 & 90.8 & 8.1 & 95.3 & 2.7 & 93.5 & 7.8 \\
\hline Pirimiphos-methyl & -1.2 & 0.003 & 5 & 81.9 & 8.8 & 89.6 & 2.8 & 84.1 & 7.0 \\
\hline Prochloraz & 6.2 & 0.003 & 0.05 & 77.9 & 8.3 & 85.6 & 3.8 & 81.5 & 7.7 \\
\hline Prometryn & 2.4 & 0.002 & - & 92.4 & 6.9 & 93.4 & 3.9 & 93.2 & 7.6 \\
\hline Tebuconazole & 7.7 & 0.003 & 0.02 & 72.2 & 11.2 & 86.9 & 5.6 & 76.0 & 10.2 \\
\hline Thiabendazole & -1.2 & 0.002 & 0.05 & 31.6 & 7.7 & 29.6 & 2.3 & 31.7 & 7.1 \\
\hline Thiacloprid & -2.4 & 0.002 & 0.05 & 62.6 & 14.2 & 80.9 & 2.7 & 65.7 & 9.9 \\
\hline Triadimenol & -0.8 & 0.003 & - & 78.4 & 9.2 & 80.5 & 2.9 & 82.9 & 8.0 \\
\hline Triazophos & -5.7 & 0.003 & 0.02 & 59.2 & 11.4 & 73.2 & 4.6 & 62.9 & 7.0 \\
\hline
\end{tabular}

recovery and RSD in accordance to previous observations during the method validation. The samples of blank matrix confirm its selectivity.

\section{Samples analyses}

All the samples did not present residue of the pesticides monitored in this work.

No other study quantifies pesticide residues in quinoa either. For example, in determination of 15 mycotoxins in samples purchased in different local markets from Granada (Spain) there were no positive samples (Benson et al., 2014), and samples collected during 2000 and 2001 in Germany $(n=5)$ were free of the toxins investigated (13 trichothecene toxins) (Worm et al., 2006).

\section{CONCLUSIONS}

A LC-MS/MS method combined with a sample treatment based on QuEChERS has been proposed for the determination of 42 pesticides in quinoa samples. This method has shown to be a suitable choice for the treatment of samples in pesticides determination, providing good recoveries and precisions and a quick determination of a 
large number of pesticides in a single run. No pesticides residues were observed in the analyzed samples.

\section{ACKNOWLEDGMENTS}

The authors acknowledge fundings support from Fundação de Amparo à Pesquisa do Estado de São Paulo process FAPESP 10/18316-6 and Roberto Valdivia main director of the Centro de Investigación de Recursos Naturales y Medio Ambiente CIRMA for the sampling process of quinoa.

\section{Author's contributions}

Franz Zirena Vilca. Analytical method developer and responsible by the adjust of the QuEChERS method.

Graziela Cristina Rossi. Moura Andrade. Assistance during the adjust to the LC-MS/MS conditions.

Walter Alejandro. Zamalloa Cuba, Assistance of laboratory during preparation of sample for the analytical analysis.

Valdemar Luiz. Tornisielo. Leader of the research group.

\section{REFERENCES}

Anastassiades, M., Lehotay, S. J., Stajnbaher, D. and Schenck, F. J. 2003a. Fast and easy multiresidue method employing acetonitrile extraction/partitioning and "dispersive solid-phase extraction" for the determination of pesticide residues in produce.

J. AOAC Int. 86: 412-431.

Anastassiades, M., Lehotay, S. J., Stajnbaher, D. and Schenck, F. J. 2003b. Fast and easy multiresidue method employing acetonitrile extraction/partitioning and \&quot;dispersive solidphase extraction\&quot; for the determination of pesticide residues in produce. J. AOAC Int. 86:412-431.

Andrade, G., Monteiro, S. H., Francisco, J. G., Figueiredo, L. A., Botelho, R. G. and Tornisielo, V. L. 2015. Liquid chromatographyelectrospray ionization tandem mass spectrometry and dynamic multiple reaction monitoring method for determining multiple pesticide residues in tomato. Food Chem. 175: 57-65.

Barriga, R. E. O., Cuba, W. A. Z., Tornisielo, V. L. and Vilca, F. Z. 2016. Determination of organochlorine pesticides in organic quinoa grains (Chenopodium quinoa Willd.) by GC-mu ECD, using the QuEChERS method. Revista Investigaciones AltoandinasJournal of High Andean Research. 18: 19-26.

Bluthgen, A. 2001. Organochlorine compounds in milkfat - Suitability of consumer protection instruments and problems at their use from DDT to dioxins and furans. Kiel. Milchwirtsch. Forschungsber.53:219-238.

Cesar, A., Lia, L. R. B., Pereira, C. D. S., Santos, A. R., COrtez, F. S., CHoueri, R. B., De Orte, M. R. and Rachid, B. R. F. 2014. Environmental assessment of dredged sediment in the major Latin American seaport (Santos, Sao Paulo - Brazil): An integrated approach. Sci. Total Environ. 497: 679-687.

Cogne, J. P., Chen, Y., Courtillot, V., Rocher, F., Wang, G. Q., Bai, M. X. and You, H. Z. 1995. A Paleomagnetic study of mesozoic sediments from the junggar and turfan basins, Northwestern
China. Earth Planet. Sci. Lett. 133: 353-366.

Da Silva, S. F. G., Bruning, I., Montone, R. C., Taniguchi, S., Cascaes, M. J., Dias, P. S., Lavandier, R. C., Hauser-Davis, . A. and Moreira, I. 2013. Polybrominated Diphenyl Ethers (PBDES) and Polychlorinated Biphenyls (PCBS) in Mussels and Two Fish Species from the Estuary of the Guanabara Bay, Southeastern Brazil. Bull. Environ. Contam. Toxicol. 91:261-266.

Demirtas, B., Parlakay, O. and Tapki, N. 2015. Organic food awareness in Turkey. Emir. J. Food Agric. 27(5): 407-415.

Diez, C., Traag, W. A., Zommer, P., Marinero, P. and Atienza, J. 2006. Ministério da Agricultura, Pecuária e Abastecimento. AGROFIT: Sistema de Agrotóxicos Fitossanitários.Comparison of an acetonitrile extraction/partitioning and \&quot;dispersive solid-phase extraction\&quot; method with classical multi-residue methods for the extraction of herbicide residues in barley samples. J. Chromatogr. A. 1131: 11-23.

Djaman, K., V Bado, B. and C Mel, V. 2016. Effect of nitrogen fertilizer on yield and nitrogen use efficiency of four aromatic rice varieties Emir. J. Food Agric. 28(2): 126-135.

FAO. 2015. FAOSTAT [Online]. Available: http://faostat3.fao.org/ browse/Q/QC/E [Accessed 07/12/15].

Feeley, M. and Brouwer, A. 2000. Health risks to infants from exposure to PCBs, PCDDs and PCDFs. Food Add. Contam., 17:325-333.

Guzzella, L., Roscioli, C., Vigano, L., Saha, M., Sarkar, S. K. and Bhattacharya, A. 2005. Evaluation of the concentration of $\mathrm{HCH}$, DDT, HCB, PCB and PAH in the sediments along the lower stretch of Hugli estuary, West Bengal, northeast India. Environ. Int. 31:523-534.

Jacobsen, S. E. and Christiansen, J. L. 2016. Some Agronomic Strategies for Organic Quinoa (Chenopodium quinoa Willd.). J. Agron. and Crop Sci. 202, 454-463.

Jakimska, A., Kot-Wasik, A. and Namiesnik, J. 2014. The Current State-of-the-Art in the Determination of Pharmaceutical Residues in Environmental Matrices Using Hyphenated Techniques. Crit. Rev. Anal. Chem. 44: 277-298.

Kasiotis, K. M., Emmanouil, C., Anastasiadou, P., PapadiPsyllou, A., Papadopoulos, A., Okay, O. and Machera, K. 2015. Organic pollution and its effects in the marine mussel Mytilus galloprovincialis in Eastern Mediterranean coasts. Chemosphere, 119: S145-S152.

Mitkona, I. 2016. Effects of organic products with insecticidal action on key onsect pests in alfalfa seed producction. Emir. J. Food Agric.29(9):609-615.

Nakata, H., Kannan, K., Nasu, T., Cho, H.-S., Sinclair, E. and Takemura, A. 2006. Perfluorinated contaminants in sediments and aquatic organisms collected from shallow water and tidal flat areas of the Ariake Sea, Japan: Environmental fate of perfluorooctane sulfonate in aquatic ecosystems. Environ. Sci. Tecnol., 40:4916-4921.

Pinto, C. G., Martin, S. H., Pavon, J. L. P. and Cordero, B. M. 2011. A simplified Quick, Easy, Cheap, Effective, Rugged and Safe approach for the determination of trihalomethanes and benzene, toluene, ethylbenzene and xylenes in soil matrices by fast gas chromatography with mass spectrometry detection. Analytica Chimica Acta, 689: 129-136.

Radman, S., Žutić, I., Fabek, S, Šic, J., Benko, B., Toth, N. and Čoga, L. 2015. Influence of nitrogen fertilization on chemical composition of cultivated nettle. Emir. J. Food Agric. 27(12): 889-896

Radovic, T., Grujic, S., Petkovic, A., Dimkic, M. and Lausevic, M. 2015. Determination of pharmaceuticals and pesticides in river sediments and corresponding surface and ground water in the Danube River and tributaries in Serbia. Environ Monit 
Assess.187(1):4092.

Ramalhosa, M. J., Paiga, P., Morais, S., Delerue-Matos, C. and Oliveira, M. 2009. Analysis of polycyclic aromatic hydrocarbons in fish: evaluation of a quick, easy, cheap, effective, rugged, and safe extraction method. J. Sep. Sci. 32:3529-3538.

Stentiford, G. D., Longshaw, M., Lyons, B. P., Jones, G., Green, M. and Feist, S. W. 2003. Histopathological biomarkers in estuarine fish species for the assessment of biological effects of contaminants. Mar. Environ. Res. 55:137-159.

Tiyagi, S. A., Rose, S. and Zehra, I. M. 2015. Evaluation of organic matter, bio-inoculants and inorganic fertilizers on growth and yield attributes of tomato with respect to the management of plant-parasitic nematodes. Emir. J. Food Agric. 27(8): 602-609.

Vuorinen, P. J., Keinanen, M., Vuontisjarvi, H., Barsiene, J., Broeg, K., Forlin, L., Gercken, J., Kopecka, J., Koehler, A., Parkkonen, J., Pempkowiak, J. and Schiedek, D. 2006. Use of biliary PAH metabolites as a biomarker of pollution in fish from the Baltic Sea. Mar. Pollut. Bull. 53:479-487.

Wen, Z.-H., Chen, L., Meng, X.-Z., Duan, Y.-P., Zhang, Z.-S. and Zeng, E. Y. 2014. Occurrence and human health risk of wastewater-derived pharmaceuticals in a drinking water source for Shanghai, East China. Sci. Total Environ. 490:987-993. 